\title{
EFFECTIVENESS OF PHYSICAL THERAPY COMBINED WITH ELECTRO STIMULATION FOR PATIENTS WITH LUMBAR PART DISC HERNIATION
}

\author{
Andrius Švedas ${ }^{1}$, Eglè Lendraitiene $\dot{e}^{1}$, Aiva Karpavičienè $\dot{\mathbf{e}}^{2}$ \\ Lithuanian University of Health Sciences ${ }^{1}$, Kaunas, Lithuania \\ Lithuanian Sports University', Kaunas, Lithuania
}

\begin{abstract}
Background. The aim of the study was to evaluate the effectiveness of physiotherapy combined with electro stimulation, for patients with spinal disc herniation in lumbar part.

Methods. The study involved 38 people, 18 men and 20 women. The average age of all subjects was $29.84 \pm$ 4.65 years. All subjects participated in the study for eight weeks, $30-45$ minutes, three times a week. They were randomly divided in to three groups: two experimental and one control group. The first experimental group (12 people) participated in physical therapy combined with electro stimulation; the second experimental group (14 people) participated in physical therapy combined with placebo (fake) electro stimulation, and the third (control) group (12 people) participated in physical therapy treatments. All groups before and after the treatment performed trunk (flexor, extensor, lateral musculature) muscular endurance tests (McGill), analogue pain scale evaluation, and $\mathrm{SF}-36$ questionnaire.

Results. After eight weeks of physical therapy combined with electro stimulation average numbers of analogue pain scale results decreased statistically significantly by $2.17 \pm 1.11(p<.05)$, trunk extensors $(33.00 \pm 12.78)$, flexors $(31.67 \pm 9.15)$ and lateral left $(20.25 \pm 2.80) /$ right $(19.50 \pm 3.71)$ musculature differences were statistically significant $(p<.05)$. Physical therapy and placebo (fake) electro stimulation group and physical therapy group did not show statistical significance for all the tests except for analogue pain scale test $(1.29 \pm 0.83$ and $1.92 \pm 1.08)$.

Conclusion. Physical therapy combined with electro stimulation applied for eight weeks for 25-39-year-old adults suffering from lumbar part disc herniation is an effective way to enhance trunk flexors, extensors, right/left lateral muscular endurance and reducing lumbar part back pain.
\end{abstract}

Keywords: muscles, electro stimulation, physiotherapy, placebo.

\section{INTRODUCTION}

$\mathrm{L}$ ower back pain occurs for people all ages, for both genders and different ethnical groups (Ščiupokas, 2005). Approximately nine out of ten adults experience back pain at some stage in their life, and ten out of twenty working adults suffer from back pain each year (Parel, 2007). Relapses in pain $(60 \%)$ and work absences $(33 \%)$ are common, making lower back pain one of the most expensive conditions in societies. The total cost counted with the management of lower back pain in Australia is at 9.17 billion Australian dollars, with the cost of indirect care and productivity losses contributing
8.15 billion Australian dollars of this total figure (Amorim et al., 2016). Non-specific lumbar part pain occurs from soft tissue such as muscle, fascia and ligaments (Mense et al, 2010). It is considered that the causes of as much as $97 \%$ of back pain cases are mechanical, with regard to static and dynamic spinal dysfunction. Such pain associated with spinal (vertebral discs, joints, ligaments, muscles) degeneration processes, but only in rare cases (not more than 10\%) of the mechanical origin of back pain can lead to more serious consequences (Ščiupokas, 2005). 
Previous research has shown that patients with lower back pain who engage in moderate or high levels of physical activity have better chances in terms of pain, disability and quality of life than those who do not maintain regular levels of physical activity (Pinto et al., 2014). These patients are likely to have a new episode of lower back pain or to continue pain and that is why they seek additional health care (Enthoven, Skargren, \& Oberg, 2004). Electrical muscle stimulation helps restore normal functioning of tissues and functional status of organs (Goriniene, 2006). Also Electro stimulation can strengthen muscles and improve their function (Kuru, 2012). Electro stimulation device myha bodytec was used.

Placebo enrolment is often believed to substantially improve desired results of the patient and the researcher (Hróbjartsson, 2010). Each physical therapy procedure is determined by specific context effect on the patient, physicians should pay attention to the context in order not to increase the placebo effect (Testa \& Rossettini, 2016).

The aim of the study was to evaluate efficiency of physiotherapy combined with electro stimulation for patients with spinal disc herniation in lumbar part.

\section{METHODS}

We used basic endurance tests to examine trunk muscles: Mcgill trunk flexor, trunk extensor and the lateral musculature tests.

Trunk Flexor Test. The flexor endurance test begins with the person in a sit-up position. Person's back is at resting angle and drops to 60 degrees from the floor. Knees and hips are flexed at 90 degree angle, arms are across on the chest with the hands placed on the opposite shoulder, and the feet are secured touching the floor. The test begins when a person is holding 60 degree angle from the ground and holds that position as long as possible, there is a triangle shaped box placed $10 \mathrm{~cm}$ from the back for self-confidence and failure. Failure is determined when any part of the person's back touches the triangle box (or gets lower more than $10 \mathrm{~cm}$ from the starting position).

The second test was Trunk muscle extensor Test. The back extensors are tested with the upper body levered out over the end of the test bench or a table and with the pelvis, knees, hips secure and fastened to the bench. Hands are held crossed on the chest and placed on the opposite shoulders. Failure occurs when the upper body drops below the horizontal position. Last one of the tests is lateral right/left musculature test. Lateral musculature is tested with the person lying on the full side bridge position on left or right side separately. Legs are extended, and the top foot is placed in front of the lower foot. Subjects support themselves on one elbow and on their feet while lifting their hips off the floor to create a straight line from head to toe. Free arm is held straight near the hip. Failure occurs when the person losses the straight-head toe line and the hip gets lower the straight line (Nesser, 2008).

The SF-36 is one of questionnaires used worldwide today. It contains of 36 questions that evaluates health across eight dimensions - physical functioning, vitality, social functioning, body pain, mental health, role limitation because of physical health, role limitation because of emotional problems and basic general health. Each question answer within a dimension is combined and generates a score from 0 to 100 , where 100 means good health (Walters \& Brazier, 2003).

Electro stimulation (ES) is effective for developing physical performance. ES offers a beneficial alternative to traditional strength training. Improving muscle strength and power by the use of ES, the settings of the device (impulse intensity, stimulation frequency, impulse width, pulse type, stimulation rate) have to be exact (Filipovic, Kleinöder, Dörmann, \& Mester, 2012).

Number of analogue pain scale (NAS). The scale is divided in to 10 equal parts and determines which section patients have marked the scale. When the pain measured on a scale is $1-4$ points, it is weak pain, 5-6 moderate pain, 7-8 felt a strong pain, 9-10 points unbearable (very strong) pain (Petrikonis, 2004).

Statistical analysis. The statistical analysis was conducted using SSPS (Statistical Package for Social Science) 17.0 software. Obtained variables were used for assessing the descriptive statistical methods (mean \pm standart deviation). Continuous variable normality assumption was verified using the Kolmogorov-Smirnov test. Two independent groups were compared to quantitative values apply to Student $(t)$ criteria, if the variable distribution satisfied the distribution normality assumption. If some variables not satisfied with the distribution of normality conditions, nonparametric MannWhitney $U$ method was applied. If quantitative dependent variables satisfied normality condition, we used Student's paired test, it not - nonparametric Wilcoxon test at $p<.05$. 


\section{RESULTS}

The average score difference between all the groups (before and after the study) using numbers analogue pain scale (NAS) was significant $(p<.05)$. For the first group, the average score was $2.17 \pm 1.11$, for the second group the score was $1.29 \pm 0.83$, and for the third group average score was $1.92 \pm 1.08$ (Figure 1).

Trunk extensor test differences in results between the first $(33 \pm 12.78)$ and the second $(19.57 \pm 9.96)$ groups showed statistical significance $(p<.05)$, the first and the third $(14.83 \pm 12.39)$ group difference was statistically significant as well, but differences between the second and the third groups did not show any statistical significance (Figure 2).
Trunk extensor test results showed that statistically significant differences were between the first $(31.67 \pm 9.15)$ and the second $(17.5 \pm$ $10.7)$, the first and the third $(19.3 \pm 8.15)$ groups (Figure 3).

Groups $1(20.25 \pm 2.8)$ and $2(11.93 \pm 3.79)$, 1 and $3(11.92 \pm 4.21)$ showed statistically significant differences $(p<.05)$, but results in the second and the third group did not show statistically significant difference (Figure 4).

Differences in the trunklateral rightmusculature test result for the first $(19.5 \pm 3.71)$ and the second $(13.5 \pm 4.03)$, the first and the third $(12.91 \pm 2.34)$ groups showed statistical significance $(p<.05)$, but those of the second and the third groups did not show significance (Figure 5).
Figure 1. Differences in NAS average points between groups 1 and $2(p<.05), 2$ and 3 $(p<.05)$
Figure 2. McGill trunk extensor test. Differences between group 1 and $2(p<.05), 1$ and 3 $(p<.05)$
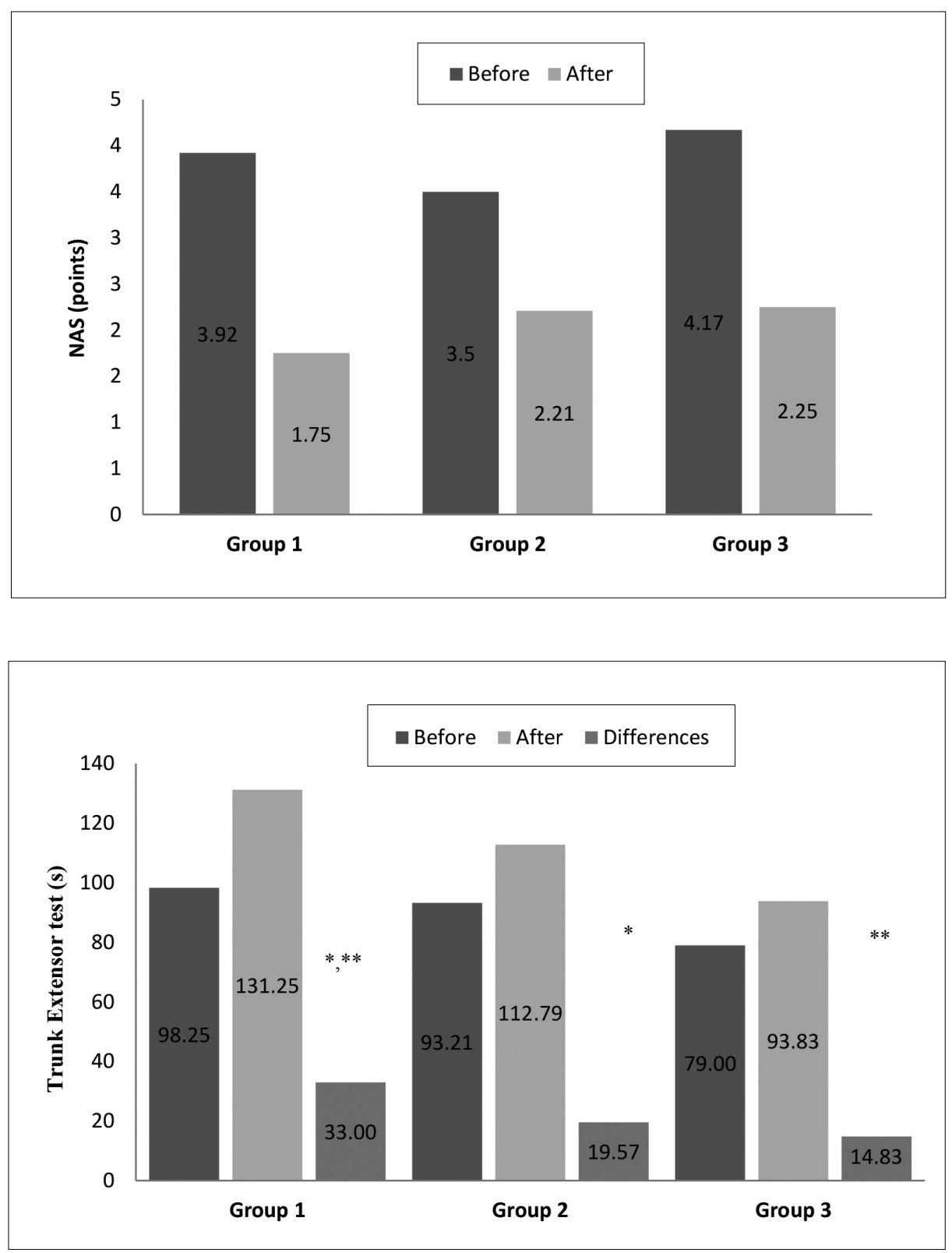

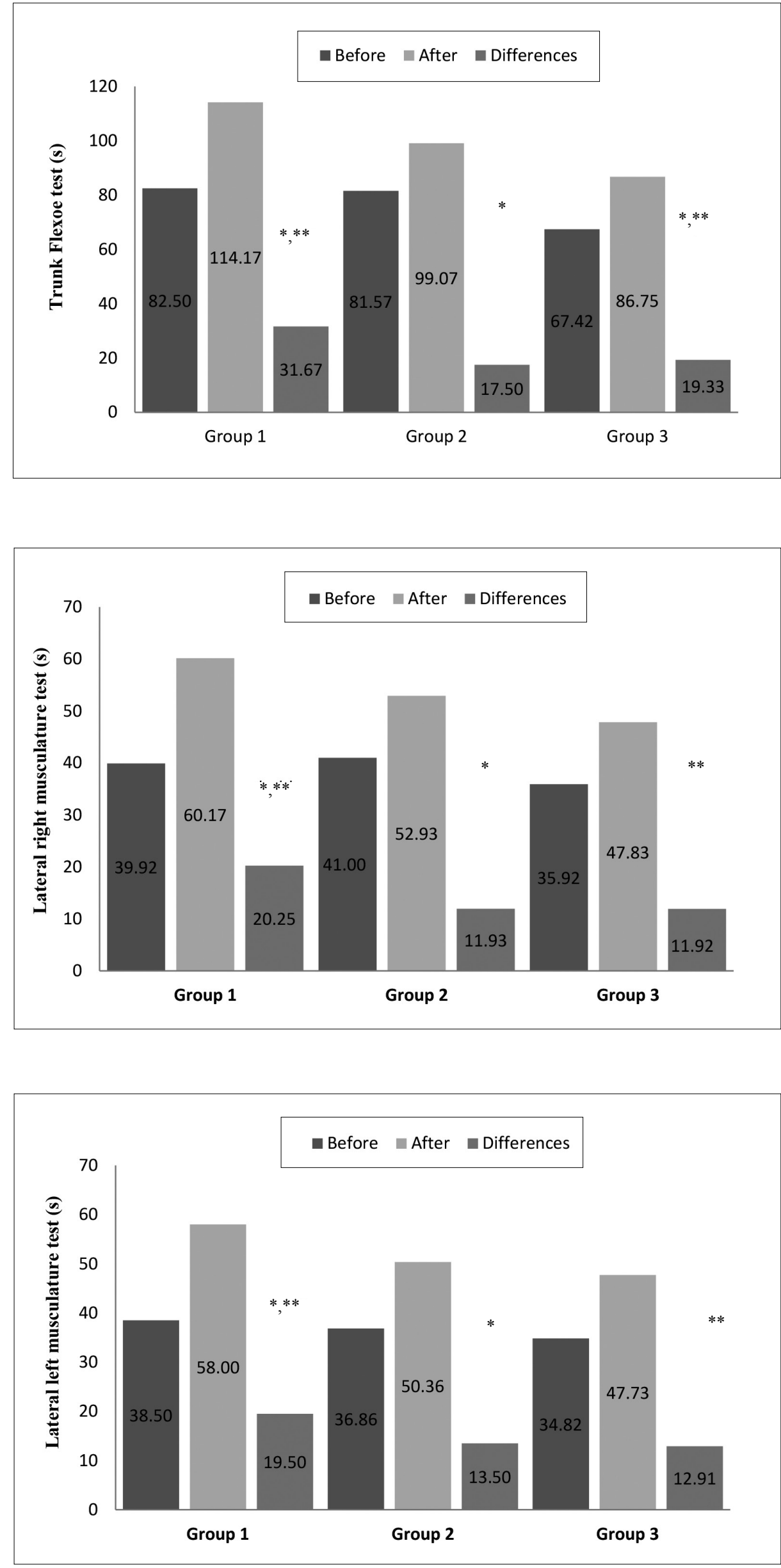

Figure 3. McGill trunk flexor test. Average differences between groups before and after the trial $(p<.05)$, groups 1 and $2(p<.05)$, groups 1 and $3(p<.05)$

Note: ${ }^{*} p<.05,{ }^{* *} p<.05$.

Figure 4. McGill trunk lateral right musculature test. Average differences between groups before and after the trial $(p<.05)$, groups 1 and 2 $(p<.05), 1$ and $3(p<.05)$

Note: ${ }^{*} p<.05,{ }^{* *} p<.05$.

Figure 5. McGill trunk lateral left musculature test. Average difference between groups before and after the trial $(p<.05)$, groups 1 and 2 $(p<.05), 1$ and $3(p<.05)$

Note. ${ }^{*} p<.05,{ }^{* *} p<.05$. 


\section{DISCUSSION}

The aim of this study was to evaluate effectiveness of physiotherapy combined with electro stimulation for patients with spinal disc herniation in lumbar part. It was found that electro stimulation combined with physical therapy achieved statistically significant results $(p<.05)$ than after physical therapy.

Wirtz, Zinner, Doermann, \& Kleinoeder (2016) presented a study aiming to investigate the effects of a multiple set squat exercise training intervention with superimposed electro stimulation on strength and power, sprint and jump performance. All groups showed improvements in leg press strength and power, countermovement and squat and sprint performance $(p<.05)$. Strength endurance occurred after six weeks of training; however our study showed statistical significant endurance results in all groups after nine weeks of exercise programme.

Babault et al. (2007) presented a study which investigated the influence of a 12-week electro stimulation training program performed by rugby players. Twenty-five rugby players participated in the study. After 12 weeks of ES training, muscle endurance enhanced statistically significantly. Those findings indicated that 12 week of electro stimulation training program have significant beneficial effect on muscle strength and power. Similar findings but in shorter time period were established by Brocherie (2005). The aim of the study was to examine the influence of short term electro stimulation training program on knee extensor endurance, skating and vertical jump performance on ice hokey players. After three weeks of training the knee extensors, skating performance increased significantly. Our rezults were simillar to other studies findings (Brocherie, Babault, Cometti, Maffiuletti, \& Chatard, 2005; Babault et al., 2007), the strength or endurance tested on subjects enhanced statistically significantly or did not have any changes, except for the study of Brocherie et al. (2005), where the vertical jump height decreased significantly and had the shortest study period. There are various studies carried out over various periods of time, but further studies are needed to set the least time possible to achieve the highest results in physical therapy used with ES.

\section{CONCLUSIONS}

Physical therapy combined with electro stimulation is an effective way to enhance trunk muscular endurance and reduce lower back pain for patients with spinal disc herniation in lumbar part.

\section{REFERENCES}

Amorim, A., Pappas, E., Simic, M., Manuela, L., Ferreira, M. L., Jennings, M., \& Ferreira, P. H. (2016). Integrating mobile health and physical activity to reduce the burden of chronic low back pain trial (IMPACT): A pilot trial protocol. BMC Musculoskeletal Disorders, 17, 36. doi:10.1186/s12891-015-0852-3

Babault, N., Brocherie, F., Cometti, G., Maffiuletti, N., \& Chatard, J. C. (2005). Electrostimulation training effects on the physical performance of ice hockey players. Medicine \& Science in Sports \& Exercise, 37(3), 455460. PMID: 15741845

Enthoven, P., Skargren, E., \& Oberg, B. (2004). Clinical course in patients seeking primary care for back or neck pain: A prospective 5-year follow-up of outcome and health care consumption with subgroup analysis. Spine, 29(21), 2458-2465. doi: 10.1097/01. brs.0000143025.84471.79

Filipovic, A., Kleinöder, H., Dörmann, U., \& Mester, J. (2012). Electromyostimulation: A systematic review of the effects of different electromyostimulation methods on selected strength parameters in trained and elite athletes. Journal of Strength and Conditioning Research, 9, 2600-2614. doi: 10.1519/JSC.0b013e31823f2cd1

Goriniene, G., \& Gorinaite, A. (2006). Fizioterapija ir kurortiniai veiksniai. Kaunas: Lietuvos kūno kultūros akademija.

Hróbjartsson, A, \& Gøtzsche, P. (2010). Placebo interventions for all clinical conditions. Cochrane Database System Review, 1, CD003974.

Kuru, T., Yaliman, A., \& Derel, E., (2012). Comparison of efficiency of Kinesio taping and electrical stimulation in patients with patellofemoral pain syndrome. Turkish Association of Orthopaedics and Traumatology, 46(5), 385-392.

Mense, S., Robert, D., \& Gerwin, A. (2010). Muscle pain: Diagnosis and treatment. Heidelberg: Springer. doi: 10.1007/978-3-642-05468-6_1 
Nesser, T. W., Huxel, K. C., Tincher, J. L., \& Okada, T. (2008). The relationship between core stability and performance in division I football players. Journal of Strength and Conditioning Research, 22(6), 1750-1754. doi: 10.1519/JSC.0b013e3181874564

Parel, A. T., \& Ogle, A. A. (2007). Diagnosis and management of acute low back pain. American Academy of Family Physicians Retrieved 15.61(6), 1779-1786. PMID: 10750882

Petrikonis, K. (2004). Nugaros skausmo diagnostika, kada skausmas neuropatinis? Reabilitacijos naujienos (pp. 2-5). Kaunas: KMU Neurologijos klinika.

Pinto, R. Z., Ferreira, P. H., Kongsted, A., Ferreira, M. L., Maher, C. G., \& Kent, P. (2014). Self-reported moderateto-vigorous leisure time physical activity predicts less pain and disability over 12 months in chronic and persistent low back pain. European Journal of Pain, 18(8), 1190 1198. doi: 10.1002/j.1532-2149.2014.00468.x
Testa, M., \& Rossettini, G. (2016). Enhance placebo, avoid nocebo: How contextual factors affect physiotherapy outcomes. Manual Therapy, 24, 65-74. doi: 10.1016/j.math.2016.04.006

Ščiupokas, A. (2005). Stuburinis ir šaknelinis skausmas. Skausmo medicina, 1(10), 9-10.

Walters, S., \& Brazier, J. (2003). What is the relationship between the minimally important difference and health state utility values? The case of the SF-6D. Health and Quality of Life Outcomes, 1, 4. doi: 10.1186/1477-75251-4

Wirtz, N., Zinner, C., Doermann, U., \& Kleinoeder, H. (2016). Effects of loaded squat exercise with and without application of superimposed ems on physical performance. Journal of Sports Science and Medicine, 15(1), 26-33. PMCID: PMC4763843 